\title{
Self-directed groupwork and social action research with francophone parents of trans children and youth in rural Quebec
}

Annie Pullen Sansfaçon ${ }^{1}$, Dominique Pineault ${ }^{1 *}$, Jennifer Davis $^{2}$, Jennifer Dyer ${ }^{3}$, James Julie ${ }^{4}$, Kimberley Ens Manning ${ }^{5}$, Julia Temple-Newhook ${ }^{3}$, Sarah Pickett ${ }^{3}$

Abstract: Parental support is an important protective factor in preventing suicide among trans youth. However, parents often struggle to accept their child's gender transition. Having access to a group and to meeting other parents facilitates the acceptance process, but support groups are rare and even more so outside urban areas. The research project discussed in this article was developed to understand specifically the experience of parents of francophone trans youth living in rural and remote communities in Quebec. A SelfDirected Group approach (Mullender, Ward and Fleming, 2013), combined with Social Action Research (Pullen Sansfaçon et al., 2015) was initiated to offer a platform for parents to explore the specificities of parenting a trans child in rural francophone Quebec. Parents were recruited through social and traditional media and a series of group meetings was planned to collect data and to facilitate the parents' mobilization as well. Despite applying the Self-Directed Groupwork principles and process, many challenges were encountered, stimulating a number of reflections on the use of self-directed groupwork and social action in remote geographical areas. This paper explores some of those challenges and discusses a possible way forward for research.

Keywords: self-directed groupwork; social action research; remote populations; parents of trans children and youth; gender diversity of children and youth; qualitative methodology

1. Université de Montréal

2. Lethbridge College

3. Memorial University of Newfoundland

4. Ryerson University

5. Université Concordia

Address for correspondence: a.pullen.sansfacon@umontreal.ca

Date of first (online) publication: 10th December 2021

* Dominique Pineault sadly passed away on 10th December 2020 


\section{Introduction}

The umbrella term 'trans and gender diverse children and youth' (TGDCY) refers to young people who do not identify with the gender they were assigned at birth. TGDCY comprise almost 2\% of the 13-17 year-old population (Lowry et al. 2019) and are at very high risk of suicide, with about 47\% having experienced suicidal ideation (Scanlon et al. 2010). Studies suggest that their experienced difficulties are not intrinsically linked to TGDCY identities, but are instead direct and indirect consequences of the negative social contexts in which they live, notably of discrimination, violence, and non-recognition as TGDCY (Scanlon et al, 2010; Connolly et al, 2016; Pullen Sansfaçon et al, 2018; Watson et al, 2016; Robert et al. 2012).

Environments that affirm TGDCY gender identities are key protective factors, linked to improvement of well-being (Travers et al. 2012). Strong parental support is shown to reduce the suicide risk among TGDCY by 93\% (Travers et al, 2012). Further, research shows that TGDCY living openly in their affirmed gender with supportive parents are as healthy as, and only marginally more anxious, than cisgender (non-TGDCY) youth (Olson et al, 2016; Durwood et al, 2017). Parental support is clearly a major protective factor in the lives of TGDCY.

However, while strong parental support is essential, not all parents are willing to support their trans child. Indeed, the vast majority of TGDCY receive little or no support from their parent(s) (Travers et al. 2012; Pullen Sansfaçon et al, 2020a). In a recent survey of TGDCY health in Canada, Taylor et al. (2020) reveals that just 50\% of youth surveyed said their mother cares very much about them, and only 36\% felt their father did. Earlier studies suggest that only about a third of youth felt their parents were strongly supportive (Travers et al, 2013)

Unsurprisingly, the process of accepting their TGDCY's transition is often described by parents as long and complicated (Pullen Sansfaçon et al, 2015). Many parents expressed experiencing grief and shock (Ehrensaft, 2011; Kuvalanka, Allen, et al, 2018; Pullen Sansfaçon et al, 2020b), isolation (Hidalgo \& Chen, 2019; Pullen Sansfaçon et al, 2015), and unmet mental health needs (Pullen Sansfaçon et al, 2020b). Some parents say their mental health needs are not met and that they require more professional or peer support (Tollit et al. 2018; Pullen Sansfaçon et al, 2020b; Temple-Newhook et al, 2018). Groupwork, and 
support groups for parents, whether online or in person, have long been considered an important tool to offer needed support for parents (Menvielle et Rodnan, 2011).

That said, support groups, as with general services for TGDCY, are primarily located in urban areas (Humble et al. 2013). Mental and behavioural services throughout rural areas remain poorly developed services (Slovak et al. 2011), thus suggesting that support for both TGDCY and their parents is rare outside large cities.

This article presents reflections on the implementation of a social action research project, drawing on self-directed groupwork, with parents of TGDCY in rural Quebec. The project aimed to facilitate support and action amongst parents of TGDCY who live outside an urban area, while simultaneously increasing understanding of the specific issues they may face, as research on rural populations remains scarce in social work (Slovak et al, 2011) We begin by briefly presenting the project's context, before discussing the main tenets of self-directed groupwork and its methodology. Next, we explore some of the issues and challenges in trying to apply them to this context, and we conclude with a discussion of possible ways forward for applying self-directed groupwork to research with populations that are rurally and/or remotely located.

\section{Rural context in Quebec and LBGTQ experiences}

In Quebec, a community is usually defined as 'rural' when it has fewer than 10,000 inhabitants, but if it is located in a remote area, it may also have more than 10,000 inhabitants (National Rural Policy, 2014). Nearly 2 million people live in rural Quebec. This population represents $25.7 \%$ of the total population of Quebec and in 2011 occupied nearly 90\% of the inhabited territory. Never in the history of Quebec has the rural population been so large (National Rural Policy, 2014).

Studies examining the experiences of the general rural population are rare (Slovak, 2011) and even more so when they specifically cover LGBT communities. In our literature review, we located only one study that considered the experience of parents of TGDCY living outside urban areas: an examination of the concerns of trans youth and their parents living in rural, remote, and urban areas of the island of Newfoundland (Temple-Newhook et al, 2018). Temple-Newhook et 
al (2018) found that rural families described lengthy and costly travel to access gender-affirming care. Additionally, we found studies that explore the experience of LGBT populations, some of which included rural trans youth in their sample. For example, a study about lesbian and gay experiences in rural Quebec, Chamberland and Paquin (2007), found that their greatest challenges relate to identity status and to navigating between living a life totally concealed (or closeted) or totally out about one's sexual identity. Indeed, rural areas are characterized by an absence of anonymity and of the separation of private and public life (Chamberland and Paquin, 2007). Accordingly, when supporting their TGDCY, parents' decisions may also be affected by rural context.

Recent research on TGDCY health in Canada shows that just under half of the sample living in rural areas received no necessary physical general health care because they did not want their parents to know, and that 14\% lacked medical help because the service was non-existent in their area, pointing out important barriers service access for Canada's rural TGDCY (Taylor et al. 2020). Furthermore, according to Hampton (2018), TGDCY may face more challenges to parental acceptance when they live in rural areas and, critically, for youth without parental support, community support becomes even more crucial to assist with their gender identity and exploration. The lack of LGBTQ role models openly living their sexuality or gender identity in rural communities may also be a barrier to gender affirmation (Hampton, 2014). Consequently, the experiences of parents of TGDCY may be impacted by the limited number of needed support services in remote regions.

\section{The projects and methodology}

This study is part of a larger federally-funded Canadian research project that includes a collaborative autoethnography of parents or advocates of TGDCY (all of whom are co-authors), an analysis of media coverage of parent activism, as well as 4 Canadian action research pilot projects aimed at better understanding and supporting the activism of parents of TGDCY. Due to the lack of research on rural TGDCY and their families and because much of Quebec's population lives outside main urban areas, it was decided to hold one pilot project in a rural area in order to better understand how this context shapes parental experience. 
The research questions for the project conducted in rural Quebec were as follows: What are the issues experienced by parents with regard to supporting their TGDCY in a rural setting? What are the needs of parents of TGDCY in rural areas? How does advocacy take shape for parents in rural areas?

Two distinct objectives were sought: first, to provide parents of TGDCY living in rural areas with a forum to discuss their experiences and identify personal, social, and political issues. Second, to increase knowledge of the issues, challenges, and opportunities that rural parents of TGDCY face.

In order to conduct a project that integrates both a research and an intervention component, the team decided to draw on social action methodology (Fleming and Ward, 2004), using a Self-Directed Group approach (Mullender, Ward and Fleming, 2013) as the data collection tool. This methodological combination was used previously in research on parents of TGDCY in Montreal, Quebec (Pullen Sansfaçon et al, 2015). According to Pullen Sansfaçon et al. (2018) this methodology facilitated both data collection on parent experiences as well as effected social change, as the project led to the development of a formal community organization that supports parents of TGDCY. Self-directed groupwork is also a recognized and compelling method that leads to the empowerment of participants (Fleming and Ward, 2017). In this context, the methodology appeared particularly relevant for a population for whom few or no services exist and where social isolation may be common. In our project, the groupwork aspect is particularly important as it allows for the development of solidarity, mutual support between parent participants, and a place to highlight similar lived experiences, at the same time as offering a powerful medium to collect data on experiences.

\section{Self-directed groupwork}

In Self-Directed Groupwork, the group facilitator fosters rather than leads the process (Fleming and Ward, 2017) by adhering to six principles that establish a democratic process of critical reflection and decision making. The principles are as follows: 
1. Inequalities and oppressions, whatever their nature, must be challenged;

2. Members have fundamental rights (the rights to participate, speak, define the type of intervention they need);

3. The intervention is based on a complex analysis of power relations (understanding of the context and constraints);

4. Collective power is acquired through groupwork;

5. People are experts in their own experiences;

6. The work must be done in a non-elitist way: the facilitator favors the animation of the group rather than its direction. (Mullender, Ward and Fleming, 2013)

Often presented as a 5-stage model, Self-Directed Groupwork, in addition to its six principles, proposes a series of steps that contribute to both the planning of the group and enacting intervention in an empowering manner.

The first step, taking stock, or the pre-planning phase of the group, consists of assembling a suitable team of facilitators and a consultant who agree on the working values and principles. This phase is followed by taking off, which refers to the planification of the group, emphasizing the importance of openness in planing !to ensure it is truly empowering for participants:

In Self-Directed Groupwork, the workers engage with users as partners to build a group, along open and user-led, rather than closed and worker-led, lines. This initiates an empowering style of work where users make key decisions such as whether to join the group, where and when to meet and what arrangements will feel least oppressive. (Mullender \& Ward 1991, p.55)

This stage of self-directed groupwork includes just enough decisions to facilitate at least one group meeting with potential participants: how they will be recruited, what an initial group structure would look like (such as time, location, format) and how this will be presented to participants during the first meeting. During this phase, potential members may begin to agree on the modalities for subsequent groupwork meetings, including if there are even enough reasons for the group to continue meeting. 
Once the group decides to continue meeting and agrees to group structure and an initial objective, the facilitators help the group to engage in the third phase, preparing to take action. Based on the above six principles, this phase aims at mobilizing the process that allows participants to explore 'what' the main challenges are, 'why' they occur, and 'how' the identified problem can be resolved (or improved) by certain actions the group can take, upon their collective reflection (Mullender Ward and Fleming, 2013). While each step is important, the 'why' question is particularly crucial because it opens onto a critical understanding of the issues participants face, encouraging participants to identify social and structural causes at the root of their issues, rather than focusing on individual difficulties, as found in other types of groupwork (Mullender, Fleming and Ward, 2013).

Once the group has explored the problem, its roots causes and possible solutions, it moves to the taking action phase, which requires participants to enact the plans formulated earlier. During this stage, the group should continue to question themselves to review and plan for future actions. The final stage, taking over, happens when the group is autonomous enough to continue without the facilitator. Mullender et al (2013) warn self-directed groupwork facilitators to leave in a timely manner, because there is great potential for group dissolution at the stage.

Ultimately, self-directed groupwork proposes a systematic process of empowerment among participants that is clearly anchored in specific values. According to the literature (it is important to follow the principles and process, as failure to do so may result in the group failure to achieve its goals, resulting in premature collapse (Mullender et al, 2013; Pullen Sansfaçon et al, 2015)

\section{Transforming ideas into research and action}

\section{Self-directed groupwork for parents of TGDCY in rural Quebec}

In this section, we summarize how each of the steps applied to our particular project, describing both the intervention and research processes. We reflect on various aspects that were arranged to offer an empowering experience, while still gathering data on parent experiences of trans and gender diverse youth. 


\section{Taking stock}

Adhering to the approach's principles, the team began to plan the group. After agreeing on the relevance of self-directed groupwork for its empowerment potential and its flexible application to various contexts, the first author offered the research team extensive selfdirected groupwork and social action research methodology training. Once trained, the team began recruiting project facilitators in each pilot region, agreeing on the importance of recruiting facilitators knowledgeable of both the regional context and the experiences of either trans lives or of TGDCY parents. For the rural Quebec group, we recruited two women to assume the facilitator role: a Master of Social Work student from Eastern Quebec who would conduct her graduate research project in this group context (and who is the second author of this article) and a parent of a trans youth. They both showed interest in the project and expressed a desire to improve services in her region. Facilitators were given paid training, as well as opportunity to truly engage in the pre-planning process with time and resources to discuss the group's values, coherence with the principles, and visions of what service should be offered to TGDCY within a trans-affirming perspective (Ehrensaft, 2006). Regular supervision and consultancy took place throughout the project, including after each group meeting so as to reflect on content, process and next steps. Engaging cofacilitators in preplanning of the research group allowed them to fully understand the principles and process of SDG, and prepare them to collect the data through a careful process of facilitation, drawing from open questions inspired by the SDG groupwork process, rather than expecting to be provided with fully developed group interview questions.

\section{Taking off}

Once the facilitators were trained, they explored together possible venues to hold the group in Bas-Saint-Laurent, their home region. The venue needed to be accessible and offer childcare. We agreed to hold the group in a local family organization which, in exchange for a fee, would organise child-care during the group meetings. The community organization was centrally located in Rimouski, the largest Eastern city in the province and a drive of 3+ hours from Quebec City. Rimouski was also considered central within the Bas-Saint-Laurent region, one 
of the three regions covered by the project.

Once the venue was agreed upon, the research team submitted all necessary ethics documents to the University of Montreal research ethics committee, for the research component to be assessed. As soon as the ethics certificate was issued, the facilitator began to plan the first meeting, including the recruitment of potential participants. In line with self-directed groupwork principles, planning was as open as possible: the team only decided a date and a time, with some general objectives (research and intervention) to advertise for recruitment. The first meeting would take place during the evening in order to accommodate parents, and childcare would be offered to increase access. The possibility to join the group via Skype or BlueJeans (a cloud video conferencing system) would be provided to facilitate participant remote access from the other two regions (Iles-de-la-Madeleine and Gaspésie), as regions covered by the project were large.

Recruitment of participants was done through an information poster, approved by the ethics committee, highlighting carefully the research component of the project so as not to induce participants to take part in the group on the belief that this would be intervention. The poster was circulated widely, both in electronic and print versions. The electronic invitation to participate in the project was shared on social media, including online Quebec parents' groups. We also circulated the invitation amongst organizations in the region likely to be in contact with TGDCY or their parents, and through email and Facebook pages and education networks throughout the targeted territories. Various stakeholders working in Bas-Saint-Laurent, Gaspésie and Îles-de-laMadeleine received the poster and were invited to share it. Posters were also strategically placed throughout Rimouski, with the approval of the organizations in question. However, given the size of the territory covered by this research, it was impossible to distribute targeted, print posters everywhere.

The first session involved greeting everyone, performing icebreaker activities, and explaining the general goals of the group (research and social action aspects). Participants were also asked to help define the group's structure (timing, duration, location) and its goal and process. Participants were requested to sign a form consenting to the project's research component and encouraged to ask any other questions. At this first meeting, four parents participated. Because of the way participants were recruited, the sampling techniques for the research component of 
the project was purposive. At the end of the meeting, participants also agreed that the group would next meet two weeks later, at the same location, time and weekday.

\section{Preparing to take action}

The second session reunited five parents, including one who joined via Skype. Henceforth, the group was guided through the social action methodology process described earlier. Participation in the following meetings fluctuated, even though participants collaboratively decided on subsequent dates during each meeting. This is common in selfdirected groupwork because members are always free to participate or not, and to decide on preferred interventions (Mullender et al, 2013). Still, no parents participated in the third meeting; the facilitation and consultant team assumed that Halloween celebrations, planned for the day prior, may have affected participation. Two parents participated in Meeting Four, while none attended Meeting Five, either in person or online. Meeting Six was cancelled due to a snow storm and road closure. Meeting Seven attracted 4 parents, including one by phone, one online, and two in person. Meeting Eight had 2 parents in person; Meeting Nine had only one parent online, probably due to bad regional weather conditions again, and no participants attended Meeting Ten. In consultation with parents, the team decided to hold a further meeting dedicated solely to a potluck, where there was no data collection because parents and the youth met together.

Except for the last meeting at which nothing was recorded, research data was collected in the form of meeting notes. In order to facilitate transparency, notes were taken on flip-charts and then transcribed on paper. We decided on note-taking instead of audio recording because, while audio recording is more appropriate for projects based on social action research methodology, it can have a chilling effect on some participants (Pullen Sansfaçon et al, 2014). All meetings notes were then transcribed verbatim. Verbatims from the meeting were then coded, through inductive thematic analysis (Braun \& Clarke, 2006), and results are now being written up for a paper on the experience of parents living outside urban areas.

At any time, participants have access to the data collected and are invited to comment and reflect on the main results. Research notes about 
the advocacy process, group dynamics, and other useful observations about the group were recorded on paper between meetings in order to create a group record, allowing facilitators to follow up on the project.

The group discussed a range of topics, identifying 'what' were the main issues they faced, and some discussion of the 'why' was initiated, but the lack of both participants and consistent parental participation made it challenging to detail specific social and structural causes of their difficulties.

While the original research project had planned a total of 15 meetings (considered sufficient to gather data, allow for diverse participation, and develop an action, if appropriate), a total of nine parents actually attended, who participated in any of the seven meetings A core group of four parents were present from start to finish, although not all were present at each meeting. Of those 7 meetings, only 6 meetings collected data, and the remaining meetings were cancelled due to weather or participant absence.

\section{Taking action / taking over}

The participants agreed that the group was not the most appropriate format for them due to travel distance, weather, and their needs. After the final potluck, an email was sent to all participants to inform them of the participant decision to end the group. There was a consensus that the research should continue because the topic was important but that individual interviews should be used to better accommodate parents' needs.

\section{Discussion}

The application of self-directed groupwork principles and process makes it possible to mobilize group strength and begin the process of change (Mullender et al, 2013). By engaging in this process, particularly in asking the 'what', 'why' and 'how' questions, the self-directed groupwork methodology centralizes links between the personal and the social/structural, allowing for concrete changes at both levels. Hence, using self-directed groupwork questions in this research allowed the team to uncover not only what parents living in rural Quebec specifically 
experience, but also their understanding about the root cause of those very experiences. This, in terms of research material, provided us with very rich insight into their lives.

In our experience of applying Self-directed groupwork for research, and despite considerable attention to fully integrating groupwork principles and process, a number of challenges occurred, stimulating reflections and discussion among us on the use of self-directed groupwork and social action in remote geographical areas both for intervention and for research. Below we discuss the main challenges we experienced as well as possible ways to successfully integrate groupwork research with this specific population.

\section{Timing and geographical location}

Originally, we planned to conduct 15 meetings for the research, with the possibility to continue the group after the research, thus aligning with self-directed groupwork principles requiring participants to decide when and how long they want to meet. The group began on October 1, 2018, and initial planning proposed meeting bi-weekly. October was preferred because it allowed parents time to organize their school year. However, while the organization of follow-up meetings was led by participants, assuring always their mutual agreement on planned meeting times, it became difficult to complete the research as planned for several reasons related to time and geographical location, which caused major challenges.

For example, winter weather conditions adversely affected group participation. Indeed, on two occasions, road closure due to snowstorms directly obstructed attendance. On at least two other occasions, the roads were not officially closed but poor conditions may have impacted attendance. Poor weather conditions relate indirectly to geographical accessibility, known to greatly affect group accessibility (Gumper and Saltman, 1999). Another possible solution would be to hold the group during Spring to Fall, which the team decided against because Summer holidays might have greater negative impact on attendance.

The vast geographic scope of the project also made participant recruitment difficult, meaning only a small number of parents attended; however, reducing the geographical area would also lead to recruitment 
problems due to rural Quebec's low population density. For example, the area of Bas-Saint-Laurent region is $22000 \mathrm{~km} 2$, with a density of 9 inhabitants per km2, while the Gaspésie covers more than 30000 km2 with 80000 inhabitants. The Madelaine Islands represent a much smaller territory, but with no land route connected to it, in-person parent participation is extremely difficult.

Even the provision of remote access did not encourage parent participation, with only one person joining once by telephone, and one participant joining two meetings via Skype. Significantly, in the Province of Quebec, some families continue to lack or have limited internet access (CEFRIO, 2018). This may have posed an additional challenge to recruitment and retention.

Planning a research project reliant solely on group activities may be more successful where additional data collection and research methods are planned. For this particular group, we planned to rely solely on the groupwork for data collection, based on successful prior experience (Pullen Sansfaçon et al, 2015), but we soon realized this would be insufficient to meet research objectives. Indeed, because of the challenges discussed above, we could only collect data from 6 of the 15 group meetings originally planned. Hence, to complete the project's research aspect, the team decided to collect data with individual interviews, still in process at the time of writing.

Towards the project's end, participants expressed their reluctance to continue with the group because they felt no need to meet regularly, preferring to talk to each other on their own terms. On this basis, the group was terminated.

\section{Preserving confidentiality}

Another issue faced by the team relates to the application of confidentiality to self-directed groupwork in rural settings. Normally, it is advisable to plan maximum group openness, allowing participants to decide upon their participation until the last minute (Mullender et al, 2013). Hence, from the outset, the team decided it best to add as a further participation measure a registration requirement prior to formalizing the group. However, when initially given the opportunity to discuss the group structure, participants chose to keep secret the meeting location, refusing to advertise on the poster the exact time and 
location of the group due to fears about protecting anonymity, and of potential interference from curious citizens. As a result, we modified the advertisement poster (and re-submitted to ethics) to reflect the group decision that would require new parents to contact a facilitator before meetings, to verify newcomers were parents prior to receiving meeting information. While Humble et al (2013) explain that rural settings experience difficulty in establishing an anonymous place to conduct the group, in our experience the challenge was the very principle of selfdirected groupwork - open access - rather than finding a space. Holding the group in a family organization not specifically oriented towards trans needs seemed sufficient to maintain confidentiality; indeed many other parent groups met at the facility. While foregoing the location on the advertisement may have limited accessibility, and parent's rights to decide their own participation, it promoted an environment deemed safe for participants, an important principle of social work with groups (AASWG, 2010).

\section{Recommendation}

The experience of using groupwork for research in rural Quebec indisputably led to important knowledge outcomes about the applicability of groupwork in remote areas generally, a field that remains underdeveloped. This experience allowed us to identify specific issues emerging in remote contexts, such as access and confidentiality. We now conclude the article by discussing some recommendations for groupwork and research with remote communities.

While the project had to be adapted to take into consideration the specific context, we feel that we could still uphold the principle of Selfdirected groupwork by paying particular attention to the participants' expressed needs. This, we believe, had an impact not on the participants' empowerment, but instead, on our capacity to collect data because we were unable to conduct the project as we had planned according to the protocol. Indeed, parents decided that they no longer needed the group and we stopped the project prematurely. Hence, when applying groupwork such as self-directed groups to a research context, we would recommend retaining some of the project resources for alternative methods of data collection, such as individual interviews that allow 
data collection to continue. As Gumper and Saltman (1999) noticed in their research, groupwork in rural communities may be fraught with challenges, which could explain why more practitioners seem to draw benefits from individual social work. They also highlight how insufficient numbers of individuals with common problems may also intensify the challenge of drawing on groupwork for intervention in rural areas (Gumper et Saltman, (1999). In our experience of using groupwork for research, this has certainly been the case.

To mitigate low participation, Humber et al (2013) suggests providing transportation and child care in rural groupwork. While we did provide child care, the large geographical area made it impossible to provide transportation; further, some participants did not have access to the mainland, and difficult weather was a major obstacle to participants attending the group.

\section{Conclusion}

To conclude, applying a social action methodology drawn from selfdirected groupwork highlights specific challenges when applied to large rural geographical areas. That said, we found parent participation in the few group meeting they could join was positive because it allowed participants to develop connections to continue mutual support, even after the group ended. In fact, during the last meeting, parents agreed that the group was not an ideal strategy for support, but that their new connections opened pathways to continue mutual support on their own terms through their newly developed network. Self-directed groupwork has therefore facilitated a decrease in social isolation, according to selfreported parent experience, despite their lack of direct collective social action about the problems they identified in the process initially.

\section{References}

Braun, V.\& Clarke, V. (2006) Using thematic analysis in psychology, Qualitative Research in Psychology, 3, 2, 77-101

CEFRIO (2018) L'enquête NETendances 2018 : Portrait numérique des foyers québécois. Quebec: Bibliothèque et Archives nationales du Québec 
Connolly, M. D., Zervos, M. J., Barone, C. J. II, Johnson, C. C. \& Joseph, C. L. (2016) The mental health of transgender youth: advances in understanding. J Adolesc Health, 59, 5, :489-495

Durwood, L., McLaughlin, K. A. \& Olson, K. R. (2017) Mental Health and SelfWorth in Socially Transitioned Transgender Youth. Journal of the American Academy of Child \& Adolescent Psychiatry, 56,2, 116-123

Gumpert, J. \& Saltman J.E. (1999) Social Group Work Practice in Rural Areas: The Practitioners Speak. Social Work with Groups, 21, 3, 19-34

Fleming, J. \& Ward, D. (2017) Self-directed Groupwork: Social justice through social action and empowerment. Critical and Radical Social Work, 5, 1, 75-91

Hampton, L. (2018) Supporting Genderqueer Youth in rural Communities. in E.Meyer, and A. Pullen Sansfaçon (Eds.) Supporting Gender Creative and Transgender Youths: Family, Schools and Community in action. (revised ed.) California: Peter Lang Press (pp. 267-284)

Hidalgo, M. A. \& Chen, D. (2019) Experiences of Gender Minority Stress in Cisgender Parents of Transgender/Gender-Expansive Prepubertal Children: A Qualitative Study. Journal of Family Issues, 40, 7, 865-886

Humble, M.L., Lewis, M.L., Scott, D.L \& Herzog, G.R. (2013) Challenges in Rural Social Work Practice: When Support Groups Contain Your Neighbors, Church Members, and the PTA. Social Work with Groups, 36, 2-3, 249-258

Kuvalanka, K. A., Mahan, D. J., McGuire, J. K. \& Hoffman, T. K. (2018) Perspectives of Mothers of Transgender and Gender-Nonconforming Children With Autism Spectrum Disorder. Journal of Homosexuality, 65, 9, 1167-1189

Lowry, J. R., Andrzejewski, J., Barrios, L. C., Demissie, Z., McManus, T., Rasberry, C. N., Robin, L. \& Underwood, J. M. (2019) Transgender Identity and Experiences of Violence Victimization, Substance Use, Suicide Risk, and Sexual Risk Behaviors Among High School Students - 19 States and Large Urban School Districts, 2017. MMWR: Morbidity and Mortality Weekly Report. 2019, 68, 67-71

Menvielle, E.J. et Rodnan, E.A. (2011) A Therapeutic Group for Parents of Transgender Adolescents. Child Adolesc Psychiatric Clin N Am, 20, 733-74

Mullender, A. and Ward, D. (1991) Self-Directed Groupwork: Users Take Action for Empowerment. London: Whiting and Birch

Mullender, A., Ward, D. \& Fleming, J. (2013) Empowerment in Action: Self-Directed Groupwork. Basingstoke(UK): Palgrave Macmillan

Olson, K. R., Durwood, L., DeMeules, M. \& McLaughlin, K. A. (2016) Mental Health of Transgender Children Who Are Supported in Their Identities. Pediatrics, 137, 3 
Pullen Sansfaçon, A., Dumais Michaud, A.A., and Robichaud, M.J. (2018b) Transforming challenges into action: Researching the experience of parents of gender creative children through social action and self-directed groupwork. in E.J. Meyer, E. and A. Pullen Sansfaçon (Eds.) Supporting Gender Creative and Transgender Youths: Family, Schools and Community in action. , A. (2nd ed.) New York: Peter Lang (pp 249-266)

Pullen Sansfacon, A, Gelly, M. Faddoul M, and LEE OJ. (2020a) Parental support and non-support of trans youth: Towards a nuanced understanding of forms of support and trans youth's expectations. Revue internationale Enfances Familles Générations, 36. https://doi.org/10.7202/1078016ar

Pullen Sansfaçon, A. Hébert, W. Ou Jin Lee, E. Faddoul, M. Tourki, D and Bellot, C. (2018) Digging beneath the surface: results from stage one of a qualitative analysis of factors influencing the well-being of trans youth in quebec. Journal of Transgenderism, 19, 2, 184-202. DOI:10.1080/15532739.2018.1446066

Pullen Sansfaçon, A., Kirichenko, V., Holmes, C., Feder, S., Lawson, M. L., Ghosh, S., Ducharme, J., Temple Newhook, J., and Suerich-Gulick, F. (2020b) Parents' journeys to acceptance and support of gender-diverse and trans children and youth. Journal of Family Issues, 41, 8., 1214-1236. https://doi. org/10.1177/0192513X19888779

Pullen Sansfaçon, A., Robichaud, M.J., and Dumais-Michaud, A.A. (2015) The experience of parents who support their children's gender variance. Journal of LGBT Youth, 12, 39-63

Pullen Sansfaçon, A., Ward, D., Dumais Michaud, A.A., Robichaud, M.J, and Clegg, A. (2014) Working with parents of gender variant children: using social action as an emancipatory research framework. Journal of Progressive Human Services, 25, 3, 214-229

Roberts, A. L., Rosario, M., Corliss, H. L., Koenen, K. C. et Bryn Austin, S. (2012) Childhood gender noncomformity: A risk indicator for childhood abuse and posttraumatic stress in youth. Pediatrics, 129, 3, 410-417

Scanlon, K., Travers, R., Coleman, T., Bauer, G. and Boyce, M. (2010) Ontario's Trans Communities and Suicide: Transphobia Is Bad for Our Health.. Trans PULSE E-Bulletin, 1, 2. [Accessed 05/12/2021 at Trans PULSE. https:// transpulseproject.ca/wp-content/uploads/2010/11/E2English.pdf]

Slovak, K., Sparks A. \& Hall, S. (2011) Attention to Rural Populations in Social Work's Scholarly Journals. Journal of Social Service Research, 37, 4, 428-438 Taylor, C., Peter, T., McMinn, T. L., Elliott, T., Beldom, S. \& Ferry, A. (2011) Every class in every school: The First National Climate Survey on Homophobia, Biphobia, and Transphobia in Canadian Schools. Final report. Toronto, ON: Egale Canada Human Rights Trust. [Accessed Accessed 05/12/2021 at 
https://egale.ca/wp-content/uploads/2011/05/EgaleFinalReport-web.pdf] Taylor, A.B., Chan, A., Hall, S.L., Saewyc, E. M. \& the Canadian Trans \& Non-binary Youth Health Survey Research Group (2020) Being Safe, Being Me 2019: Results of the Canadian Trans and Non-binary Youth Health Survey. Vancouver, Canada: University of British Columbia Stigma and Resilience Among Vulnerable Youth Centre

Temple Newhook, J., Benson, K., Bridger, T., Crowther, C., and Sinnott. R. (2018). The TransKidsNL Study: Healthcare and support needs of transgender children, youth, and families on the island of Newfoundland. Canadian Journal of Community Mental Health, 37, 2, 13-28. DOI:10.7870/ cjcmh-2018-009

Tollit, M. A., Feldman, D., McKie, G. \& Telfer, M. M. (2018) Patient and Parent Experiences of Care at a Pediatric Gender Service. Transgender Health, 3, 1, 251-256

Travers, R., Bauer, G., Pyne, J., Bradley, K. for the Trans PULSE Project, Gale, L. \& Papadimitriou, M. (2012) Impacts of Strong Parental Support for Trans Youth: A Report Prepared for Children's Aid Society of Toronto and Delisle Youth Services. [accessed 5/12/2021 at Trans PULSE: https://transpulseproject. ca/wp-content/uploads/2012/10/Impacts-of-Strong-Parental-Support-forTrans-Youth-vFINAL.pdf]

Watson, R. J., Veale, J. F. \& Saewyc, E. M. (2016) Disordered eating behaviors among transgender youth: Probability profiles from risk and protective factors. The International Journal of Eating Disorders, 49, 9, 515-522 